\title{
Ant-plant mutualism: a dietary by-product of a tropical ant's macronutrient requirements
}

\author{
Lina M. Arcila Hernández, ${ }^{1,4,6}$ Jon G. Sanders, ${ }^{2}$ Gabriel A. Miller, ${ }^{2,5}$ \\ Alison Ravenscraft, ${ }^{2,3}$ and Megan E. Frederickson ${ }^{1}$ \\ ${ }^{1}$ Department of Ecology \& Evolutionary Biology, University of Toronto, 25 Willcocks Street, Toronto, Ontario M5S 3 B2 Canada \\ ${ }^{2}$ Department of Organismic \& Evolutionary Biology, Harvard University, 26 Oxford Street, Cambridge, Massachusetts 02138 USA
}

\begin{abstract}
Many arboreal ants depend on myrmecophytic plants for both food and shelter; in return, these ants defend their host plants against herbivores, which are often insects. Antplant and other mutualisms do not necessarily involve the exchange of costly rewards or services; they may instead result from by-product benefits, or positive outcomes that do not entail a cost for one or both partners. Here, we examined whether the plant-ant Allomerus octoarticulatus pays a short-term cost to defend their host plants against herbivores, or whether plant defense is a by-product benefit of ant foraging for insect prey. Because the food offered by antplants is usually nitrogen-poor, arboreal ants may balance their diets by consuming insect prey or associating with microbial symbionts to acquire nitrogen, potentially shifting the costs and benefits of plant defense for the ant partner. To determine the effect of ant diet on an ant-plant mutualism, we compared the behavior, morphology, fitness, stable isotope signatures, and gaster microbiomes of $A$. octoarticulatus ants nesting in Cordia nodosa trees maintained for nearly a year with or without insect herbivores. At the end of the experiment, ants from herbivore exclosures preferred protein-rich baits more than ants in the control (i.e., herbivores present) treatment. Furthermore, workers in the control treatment were heavier than in the herbivore-exclusion treatment, and worker mass predicted reproductive output, suggesting that foraging for insect prey directly increased ant colony fitness. The gaster microbiome of ants was not significantly affected by the herbivore exclusion treatment. We conclude that the defensive behavior of some phytoecious ants is a by-product of their need for external protein sources; thus, the consumption of insect herbivores by ants benefits both the ant colony and the host plant.
\end{abstract}

Key words: ant-plant interactions; by-product benefits; diet balance; macronutrients; microbiome; mutualism; stable isotope analysis; trophic level.

\section{INTRODUCTION}

Mutualisms involve the exchange of goods or services between individuals of different species to their reciprocal benefit. These interactions are widely expected to be evolutionarily unstable if partners can "cheat" by taking the benefits of the mutualism without reciprocating (Sachs et al. 2004, Frederickson 2009, Jones et al. 2015). However, few studies have shown evidence of cheating, and theoretical and empirical work has described mechanisms that align the fitness interests of mutualistic partners, thereby preventing cheating (Sachs

Manuscript received 8 June 2017; revised 8 September 2017; accepted 14 September 2017. Corresponding Editor: Nathan J. Sanders.

${ }^{3}$ Present address: Center for Insect Science, University of Arizona, Tucson, Arizona 85719 USA.

${ }^{4}$ Present address: Department of Ecology \& Evolutionary Biology, Cornell University, Corson Hall, Ithaca, New York 14850 USA.

${ }^{5}$ Present address: San Diego Zoo Institute for Conservation Research, 15600 San Pasqual Valley Road, Escondido, California 92027 USA.

${ }^{6}$ E-mail: linaarcila@gmail.com et al. 2004, Frederickson 2013, 2017). Previous research has emphasized partner fidelity feedback or partner choice as explanations for why mutualists rarely cheat (Sachs et al. 2004, Frederickson 2009, Weyl et al. 2010), but a simpler possibility is that reciprocating a mutualism is not always costly (Jones et al. 2015). Indeed, "by-product benefits" likely confer stability to many mutualistic interactions, including plant-animal and animal-animal mutualisms (Sachs et al. 2004, Mayer et al. 2014).

In plant-animal mutualisms, plants often benefit as a by-product of animal foraging. For example, animals pollinate flowers as they forage for nectar or pollen and disperse seeds as they forage for fruit (Leimar and Connor 2003). Most pollinators and seed dispersers are probably not under selection to cheat because foraging directly increases animal fitness, and the pollination and dispersal services animals provide to plants are simply "happy accidents" of their foraging behavior. Instead, the outcome of mutualism (i.e., the fitness benefits realized by both partners) strongly depends on the foraging behavior and nutritional needs of the animal partner (Leimar and Connor 2003, Mayer et al. 2014, Malé 
et al. 2017). This may be especially true in facultative interactions, but is also possible even in obligate symbioses, such as ant-myrmecophyte associations.

In protective ant-plant mutualisms, ants reduce herbivory on plants that provide them with food (extrafloral nectar or food bodies) or shelter (hollow structures called domatia on myrmecophytes; e.g. Janzen 1966, Fiala et al. 1994). Ant-plant mutualisms have been studied through the lens of cheating and exploitation since the publication of Janzen's classic paper on a Pseudomyrmex species that parasitizes swollen-thorn acacias (Janzen 1975, see also Gaume and McKey 1999, Tillberg 2004, Frederickson 2009, Mayer et al. 2014), but the idea that ants may benefit plants as a by-product of their foraging behavior has received less attention than other mechanisms that can stabilize mutualisms (e.g., Weyl et al. 2010). During the early evolution of ant-plant mutualisms, ants likely foraged for insect prey on plants, reducing insect damage to plants as a by-product. Gradually, many plants evolved extrafloral nectaries, food bodies, and domatia to attract greater numbers of ants, decreasing herbivory and perhaps making ants less dependent on insects for food (Mayer et al. 2014, Weber and Agrawal 2014). Most tropical arboreal ants are omnivorous to varying degrees and consume some combination of arthropod prey, extrafloral nectar, food bodies, and honeydew excreted from hemipterans (Blüthgen et al. 2003, Davidson 2003). They may additionally receive important nutritional inputs from microbes that may modify the costs and benefits of the ant-plant interaction (Davidson 2003, Russell et al. 2009, Mayer et al. 2014, Sanders et al. 2014). Ants that eat arthropod prey may still benefit plants simply as a byproduct of their foraging (Frederickson et al. 2012). Alternatively, if the ants do not consume herbivores, as is the case for some Pseudomyrmex ants defending Acacia trees (Janzen 1966), they may depend heavily on their host plants for food. For these ants, plant defense may be costly to the colony, at least in the short term. In the long term (i.e., over the lifetime of an ant colony), however, plant defense should still be beneficial to these ants because ridding plants of herbivores promotes plant growth and the production of additional food and nesting sites for the ant colony.

In a previous study (Frederickson et al. 2012), we determined the costs and benefits of having an ant partner (Allomerus octoarticulatus) for a common Amazonian myrmecophyte (Cordia nodosa). Here, we determine costs and benefits of the mutualism for the ant partner. We investigated several lines of evidence linking changes in ant foraging behavior and diet (i.e., trophic level, compensatory foraging, microbiome) to ant fitness (i.e., ant mass and size, colony size, and number of reproductives). By experimentally excluding most herbivorous insects from saplings of $C$. nodosa for nearly a year, we investigated whether A. octoarticulatus ant colonies benefit directly from patrolling $C$. nodosa and potentially eating insect herbivores, or whether colonies of this species pay a shortterm cost to defend their host plants against herbivores.
We expand on previous analyses that showed that ant colony size did not differ between herbivore-excluded and control ant colonies after almost a year in the experimental treatments (Frederickson et al. 2012). We estimated colony biomass in both treatments and investigated how colony size and worker mass jointly influence the number of reproductives produced by $A$. octoarticulatus ant colonies, an important fitness component.

We also explored whether the experimentally imposed shift in diet (i.e., the presence or absence of insect prey) affected ant foraging for proteins vs. carbohydrates and ant trophic level, as measured by analysis of nitrogen and carbon stable isotope ratios. Insects do not forage indiscriminately for macronutrients, but instead adjust their foraging behavior to maintain appropriate protein:carbohydrate (P:C) ratios (Raubenheimer and Simpson 1999, Dussutour and Simpson 2009) and extremely unbalanced P:C ratios often have negative consequences for insect performance (Dussutour and Simpson 2009, 2012). Other studies on phytoecious ants have shown that carbohydrate-rich diets increase ant aggression toward insect herbivores (Ness et al. 2009, Pringle et al. 2011, but see Mcglynn and Parra 2016). We asked whether ants in A. octoarticulatus colonies that had been prevented from foraging for insect prey recruited in larger numbers to protein or carbohydrate baits, compared to control colonies. We expected colonies in the herbivore-exclusion treatment to be protein starved and to recruit more to protein baits. Alternatively, finding that herbivore-exclusion did not affect ant foraging for protein vs. carbohydrates might suggest that insects are a minor component of $A$. octoarticulatus's diet, or that this ant species has other ways of overcoming nitrogen limitation, such as via symbiotic bacteria.

Microbial symbionts can perform important functions for their host and in some cases have coevolved with them (Moran 2001). If ants have bacteria that help them overcome nutritional deficiencies in their diets, they might be able to survive feeding only on extrafloral nectar or food bodies, even if these plant-derived foods are nutritionally imbalanced (Janson et al. 2008). There is also substantial interest in understanding how diet shapes the gut microbiomes of animals; here we describe how diet affected the bacterial communities in the $A$. octoarticulatus gaster. Across mammals, species with similar diets tend to have similar gut microbiomes (Ley et al. 2008, Muegge et al. 2011). For example, eating a predominantly animal- or plant-based diet changes the abundance of many taxa in the human gut microbiome (David et al. 2014). In ants, diet and the composition of the gut microbiome are correlated across lineages (Russell et al. 2009, Anderson et al. 2012). Some of these gut microbes may upgrade, recycle, or even fix nitrogen for their ant hosts (Davidson 2003, Russell et al. 2009, Anderson et al. 2012, Six 2013), although experimental demonstrations are few (but see Feldhaar et al. [2007] for details of how Blochmannia compensates for nitrogen-poor diets in Camponotus). To our knowledge, no 
field study has yet investigated how microbes residing in ant gasters respond to experimental shifts in diet in the wild. We characterized the gaster microbiome of $A$. octoarticulatus using $16 \mathrm{~S}$ amplicon pyrosequencing and quantitative PCR, and compared our results between ants that had foraged or not on insect prey over a year. We thus determined how much the A. octoarticulatus gaster microbiome varies across ant colonies and experimental treatments. The consistent presence of particular microbial taxa across ant colonies might suggest that they carry out important functions for their hosts, while a shift in bacterial assemblages in response to treatment could indicate that bacteria are directly affected by what their hosts eat, or that ants regulate their microbiome in response to changes to their diet.

\section{Methods}

\section{Study site and system}

We carried out this study at the Centro de Investigación y Capacitación Río Los Amigos (CICRA) in the Peruvian Amazon $\left(12^{\circ} 34^{\prime} 07^{\prime \prime} \mathrm{S}, 70^{\circ} 05^{\prime} 57^{\prime \prime} \mathrm{W}\right.$, elevation 230-270 m). CICRA extends over three different habitats: upland forests, floodplain forests, and swamps. Mean monthly temperature at the station varies from $21^{\circ} \mathrm{C}$ to $26^{\circ} \mathrm{C}$ and annual rainfall ranges from 2,700 to 3,000 mm (Pitman 2008).

Cordia nodosa (Boraginaceae) is an abundant ant-plant at CICRA. It has distinctive domatia: hollow, swollen stems that house ants. C. nodosa also provides nutritional rewards to ants in the form of food bodies on the surfaces of young leaves. The ants that nest in C. nodosa ( $A$. octoarticulatus, three species in the genus Azteca, and occasionally Myrmelachista schumanni) protect their host plants against herbivores, and this benefit outweighs the cost of producing domatia and food bodies (Frederickson 2005, Frederickson et al. 2012). In this study, we focused on the obligate ant symbiont $A$. octoarticulatus (Myrmicinae). With very few exceptions, only one colony of $A$. $o c$ toarticulatus lives in an individual $C$. nodosa plant at a time; workers exclusively forage on the host plant, defending against herbivores. Allomerus octoarticulatus colonies live for an average of $7.8 \mathrm{yr}$, although their C. nodosa host plants can live for much longer ( $\sim 77 \mathrm{yr})$ and are repeatedly colonized by ants throughout their lives (Frederickson and Gordon 2009).

\section{Experimental manipulation of insect herbivores/prey}

Our experimental design is described in detail elsewhere (Frederickson et al. 2012, 2013). Briefly, we grew C. nodosa saplings with and without most insect herbivores (potential A. octoarticulatus prey) and with and without ants, in a full-factorial manner. Here, we analyze data from only the two treatments with ants: $\mathrm{A}+\mathrm{H}+$ (ants added, herbivores allowed) and $\mathrm{A}+\mathrm{H}-$ (ants added, herbivores excluded). The C. nodosa saplings used in the experiment were grown from wild-collected seeds in outdoor cages until they first produced domatia. In 2009, 52 saplings were transplanted in blocks of 4-13 $2 \times 2 \mathrm{~m}$ plots in the rainforest understory and then assigned at random to treatments. Twenty-six ant colonies were collected from naturally occurring $C$. nodosa plants at the same site; the number of workers in each colony was counted and the colonies were transferred to plants in the $\mathrm{A}+$ treatments. Insect herbivores were manipulated using mosquito nets, which were hung over all of the saplings. To exclude herbivores in the $\mathrm{H}-$ treatment, the nets were staked securely to the ground; in the $\mathrm{H}+$ treatment, the nets were raised $30 \mathrm{~cm}$ off the ground. Plants and ant colonies spent 314-329 d in the experiment.

Frederickson et al. (2012) showed that the herbivore exclusion treatment was successful, except for coccids that remained inside the domatia; herbivore damage to leaves was significantly lower on $\mathrm{H}-$ than $\mathrm{H}+$ plants. Therefore, ant colonies in the $\mathrm{H}$ - treatment were prevented from foraging for insect prey on plant surfaces, while ant colonies in the $\mathrm{H}+$ treatment had access to insect prey as a potential proteinaceous food source.

\section{Ant diet}

In June 2010, we investigated whether the ant colonies in the $\mathrm{H}$ - treatment were balancing their diet by foraging for more protein than the ant colonies in the $\mathrm{H}+$ treatments. We measured the recruitment of $A$. octoarticulatus workers in our experimental colonies to two bait types with either $3: 1$ or $1: 3$ ratios of protein (whey protein powder, InterACTIVE Nutrition International Inc. ${ }^{\circledR}$, Canada) to carbohydrates (table sugar) (modified from Dussutour and Simpson 2008). We poured the baits into 1.5-mL centrifuge tubes and attached with wires to various domatia. Both baits were present on the same tree at the same time but on different domatia. After five hours, we recorded the number of ants at these baits.

At the end of the experiment, we collected and preserved all the ants in each colony in $96 \%$ ethanol. We analyzed the ratios of stable isotopes of carbon $\left(\delta^{13} \mathrm{C}\right)$ and nitrogen $\left(\delta^{15} \mathrm{~N}\right)$ to investigate the trophic level of each colony (Blüthgen et al. 2003). We took a random sample of 20 ants per colony, removed their gasters, oven-dried them for $48 \mathrm{~h}$ at $60^{\circ} \mathrm{C}$, and weighed them (Blüthgen et al. 2003, Feldhaar et al. 2010). Stable isotope measurements on individual ants were not possible due to their small sizes. We compared the stable isotope ratios of ants in this experiment to those of naturally occurring plants, ants, insect herbivores, and predatory spiders collected at the same site (Appendix S1: Table S1). Samples were analyzed at the UC Davis Stable Isotope Facility.

\section{Colony performance}

To assess colony performance, we first counted all adult worker ants present on branches, leaves, and inside 
domatia of the host trees to determine ant colony size at the end of the experiment. Second, we measured eight morphological characters (head length, head width, scape length, mandible length, mesosoma length, mesosoma width, petiole and postpetiole length, and gaster length) on 20 worker ants per colony, following Fernández (2007). We then measured the dry mass (oven-dried for $48 \mathrm{~h}$ at $60^{\circ} \mathrm{C}$ ) of five workers per colony. Finally, to determine if worker mass is related to ant colony fecundity, we collected eight naturally occurring colonies of A. octoarticulatus (i.e., not in our main experiment), counted the number of workers and reproductives (i.e., alate males and females, as well as reproductive pupae and larvae). We also dried and weighed 20 workers from each of these eight colonies.

\section{Gaster microbiome}

We investigated the microbiome of ant gasters from this experiment by sequencing bacterial $16 \mathrm{~S}$ rRNA genes. We surface-sterilized 20 workers per colony with a $10 \%$ bleach solution for $15 \mathrm{~s}$ and rinsed them with phosphatebuffered saline (PBS) solution for $30 \mathrm{~s}$ before removing the gasters. We removed the 20 gasters with tweezers and we pooled all of them in one sample to perform a phenol: chloroform DNA extraction. We purified the DNA extractions with a silica column (DNeasy Blood \& Tissue Kit, QIAGEN ${ }^{\circledR}$, Hilden, Germany) and isopropanol precipitation. We sent the resulting extracted DNA for microbial diversity analysis to the Research and Testing Laboratory in Lubbock, Texas for bacterial tag-encoded FLX pyrosequencing (bTEFAP) using the primers Gray28F (5' TTTGATCNTGGCTCAG) and Gray519r (5' GTNTTACNGCGGCKGCTG). The sequencing library was generated by one-step PCR with 30 cycles and the bTEFAP was performed on a 454 FLX, Roche, Branford, Connecticut, USA instrument (Dowd et al. 2008).

In addition, we performed quantitative PCR (qPCR) to measure the abundance of bacteria in the same DNA samples that were used to analyze bacterial diversity. We prepared each $20-\mu \mathrm{L}$ reaction to quantify $16 \mathrm{~S}$ rRNA gene sequences with $10 \mu \mathrm{L}$ of Perfecta SYBR Green FastMix (VWR), $6.5 \mu \mathrm{L}$ of molecular grade water, $0.75 \mu \mathrm{L}$ of $338 \mathrm{~F} \quad\left(5^{\prime}\right.$ ACTCCTACGGGAGGCAGCAG) and $0.75 \mu \mathrm{L}$ of $518 \mathrm{R}$ (5' ATTACCGCGGCTGCTGCTGG) primers (Lane 1991), and $2 \mu \mathrm{L}$ of sample. The reactions were duplicated and we ran them in one cycle of $3 \mathrm{~min}$ at $95^{\circ} \mathrm{C}$, followed by 40 cycles of $30 \mathrm{~s}$ at $95^{\circ} \mathrm{C}, 1 \mathrm{~min}$ at $55^{\circ} \mathrm{C}, 30 \mathrm{~s}$ at $72^{\circ} \mathrm{C}$, and a final cycle of $1 \mathrm{~min}$ at $95^{\circ} \mathrm{C}$, $30 \mathrm{~s}$ at $55^{\circ} \mathrm{C}$, and $30 \mathrm{~s}$ at $95^{\circ} \mathrm{C}$. Absolute quantities were estimated using standard curves of Escherichia coli $16 \mathrm{~S}$ rRNA genes cloned into a plasmid and linearized, per Sanders et al. (2017).

\section{Statistical analysis}

For the Ant diet and Colony performance analyses, we omitted three blocks of the initial 13 because at least one ant colony in each of these blocks did not survive to the end of the experiment. We included block as a random factor while fitting the statistical models. We square-root transformed all count data and log-transformed all mass data to improve normality. To analyze the recruitment of ant workers to protein-rich baits, we used an ANCOVA model with herbivore treatment as a fixed factor, and recruitment of ant workers to carbohydrate-rich baits as a covariate, thereby incorporating colony activity levels into the model. We compared the carbon and nitrogen stable isotope ratios between herbivore treatments with a MANOVA test followed by linear mixed models, with block as a random factor, to clarify which variables differed between treatments.

We ran a principal component analysis on the morphological character data. Most of the variation in the data set was explained by the first and second principal components (PC1 explained 50\% and PC2 explained 14\%). We used PC1 and PC2 to compare worker size between treatments in an ANOVA. We also analyzed the worker mass and colony growth data in mixed-effects ANOVAs. We excluded one block because its ant colonies were outliers in all the analyses; during the experiment, a large tree fell near this block, creating a light gap that caused unusually rapid plant and ant colony growth. To determine if worker mass was correlated with the number of reproductives, we regressed the number of alates per colony against ant colony size (i.e., number of workers). We used the residuals of that regression to compute a second linear regression of worker mass on the number of alates.

For the molecular analyses of gaster microbiota, we included all surviving colonies in the experiment. It was not possible to amplify the samples from the $\mathrm{H}+$ treatment in one of the blocks (I), thus we could not include this sample in the analyses (final number of blocks analyzed $=11$; nine pairs and two singletons); the use of these singleton blocks ( $\mathrm{I}$ and $\mathrm{J}$ ) did not change any of the microbiome patterns found in the analyses. We used AmpliconNoise to denoise the pyrosequencing data, thereby removing most of the amplification errors and chimeras from the data set (Quince et al. 2009). Afterwards, using the Qiime platform (Caporaso et al. 2010), we aligned and clustered the sequences to produce a denoised operational taxonomic unit (OTU) table, assigning taxonomy using the RDP classifier and database (Wang et al. 2007). We omitted all OTUs that had fewer than two reads per sample to exclude rare bacteria more likely to be contaminants or errors. We computed a single rarefaction at a depth of 600 reads to account for the differences in the number of reads in each sample; blocks $\mathrm{H}, \mathrm{I}$, and the $\mathrm{H}+$ sample from $\mathrm{D}$ were excluded with this procedure because of a low number of reads. On this rarefied OTU table, we analyzed alpha diversity with Faith's Phylogenetic Diversity (PD), which is based on the phylogenetic diversity of samples, calculated with the total branch length of the bacterial tree. We examined beta diversity in a principal coordinates analysis (PCoA). To perform the PCoA, we created a distance matrix using the unweighted UniFrac algorithm. This algorithm uses the branch lengths in a 
phylogenetic tree generated with the sample sequences to test for the fraction of total branch length that is unique to one environment, providing information on presence and absence of different bacteria types. We also used a weighted UniFrac algorithm that uses the same principles as unweighted UniFrac, but weights the branches by the taxon abundance (Lozupone et al. 2007). We used PERMANOVA with the function Adonis in R $(1,000$ permutations, method = bray) to analyze the variance of the bacterial assemblages resulting from treatment and block effects. Counts of $16 \mathrm{~S}$ sequences obtained with qPCR were standardized by DNA concentrations for each sample. Statistical models were calculated in JMP (10.0.0, SAS Institute Inc., Cary, North Carolina, USA) and R (3.2.1, R Development Core Team 2015).

\section{RESULTS}

\section{Ant diet}

Ants in the $\mathrm{H}$ - treatment strongly preferred proteinrich baits; more than twice the number of ants recruited to the protein-rich baits in the $\mathrm{H}-$ (mean $\pm \mathrm{SE}$, $16.7 \pm 7.613$ workers $)$ than in the $\mathrm{H}+(7.2 \pm 4.060$ workers $)$ treatment (ANCOVA, treatment effect, $F_{1,7}=8.249$, $P=0.024)$. There was also a significant effect of the covariate (number of ants at C-rich baits, $F_{1,15}=12.412$, $P=0.003$ ), reflecting differences in activity levels among ant colonies.

Ants that developed in the presence of insect herbivores had different carbon and nitrogen isotopic signatures than ants that developed without the insect herbivores (Fig. 1; MANOVA $\left.F_{1,15}=4.7296, P=0.025\right)$. This difference was mostly due to $\delta^{13} \mathrm{C} \quad(\mathrm{H}+,-32.78 \% \pm 0.19 \%$; $\mathrm{H}-$, $-33.50 \% \pm 0.21 \% ; F_{1,8}=9.70, P=0.014$; Fig. 1 A), as

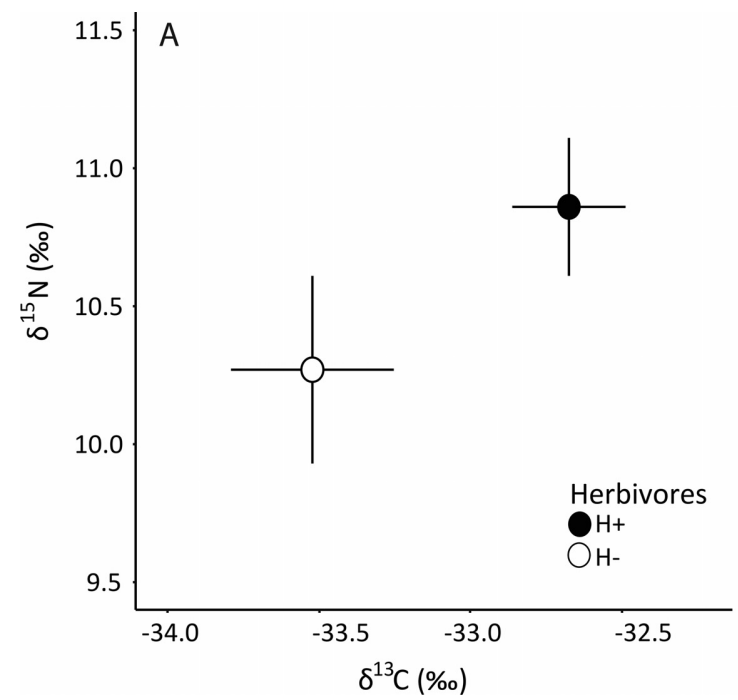

$\delta^{15} \mathrm{~N}$ did not differ significantly between treatments $\left(\mathrm{H}+, 11.01 \% \pm 0.27 \%\right.$ \% $\mathrm{H}-, 10.35 \% \pm 0.32 \% ; \quad F_{1,8}=$ 2.3731, $P=0.162$; Fig. 1C). For all the samples in the experiment, $\delta^{15} \mathrm{~N}$ was enriched compared to those of the naturally occurring reference samples (Fig. 1D), while $\delta^{13} \mathrm{C}$ values of ants in the experiment were closer to those of naturally occurring ants (Fig. 1B).

\section{Colony performance}

Elsewhere, we reported that there was no significant difference in ant colony size between treatments, although $\mathrm{H}+$ colonies were larger on average than $\mathrm{H}-$ colonies at the end of the experiment (Frederickson et al. 2012). Here, we found that workers that developed in the presence of insect prey were significantly heavier than those that did not $(\mathrm{H}+, 0.056 \pm 0.002 \mathrm{mg} ; \mathrm{H}-, 0.047 \pm$ $0.003 \mathrm{mg} ; F_{1,8}=8.013, P=0.022$; Fig. 2A), suggesting that colonies achieved a larger total biomass when they had access to insect prey. Workers also tended to be larger in the $\mathrm{H}+$ than in the $\mathrm{H}-$ treatment, although this difference was not statistically significant $\left(\mathrm{PC} 1, F_{1,8}=2.192\right.$, $P=0.177$ ). Finally, independently of colony size (i.e., worker number), worker mass explained about $36 \%$ of the variance in the number of adult reproductives in the naturally occurring colonies that we sampled $\left(F_{1,7}=\right.$ 5.433, $P=0.05$; Fig. 2B). Therefore, colonies with heavier workers make more reproductives.

\section{Gaster microbiome}

Treatment did not influence the bacterial assemblage in A. octoarticulatus gasters, in particular the alpha diversity of the gaster microbiome: $\mathrm{H}+$ and $\mathrm{H}-$ gasters were similarly diverse (Fig. 3A). The bacterial assemblage was

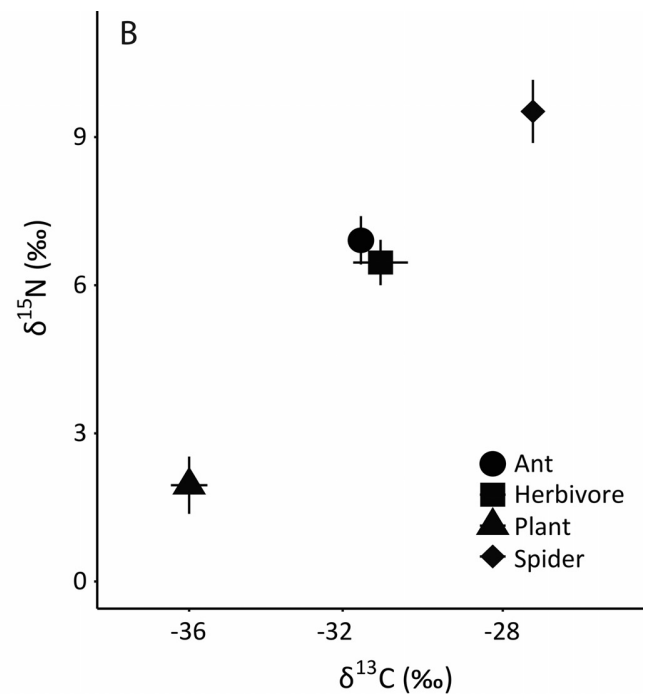

FIG. 1. (A) Carbon and nitrogen stable isotope ratios for ants in the $\mathrm{H}+$ and $\mathrm{H}-$ treatments. Open circles indicate treatments with no access to prey $(\mathrm{H}-)$, while black circles indicate treatments with access to insect prey $(\mathrm{H}+)$. (B) Carbon and nitrogen isotope ratios for naturally occurring $C$. nodosa (plant), A. octoarticulatus workers (ant), insect herbivores (coleopterans, hemipterans, etc.), and predatory spiders found on $C$. nodosa are given for reference. All values are mean $\pm \mathrm{SE}$. 

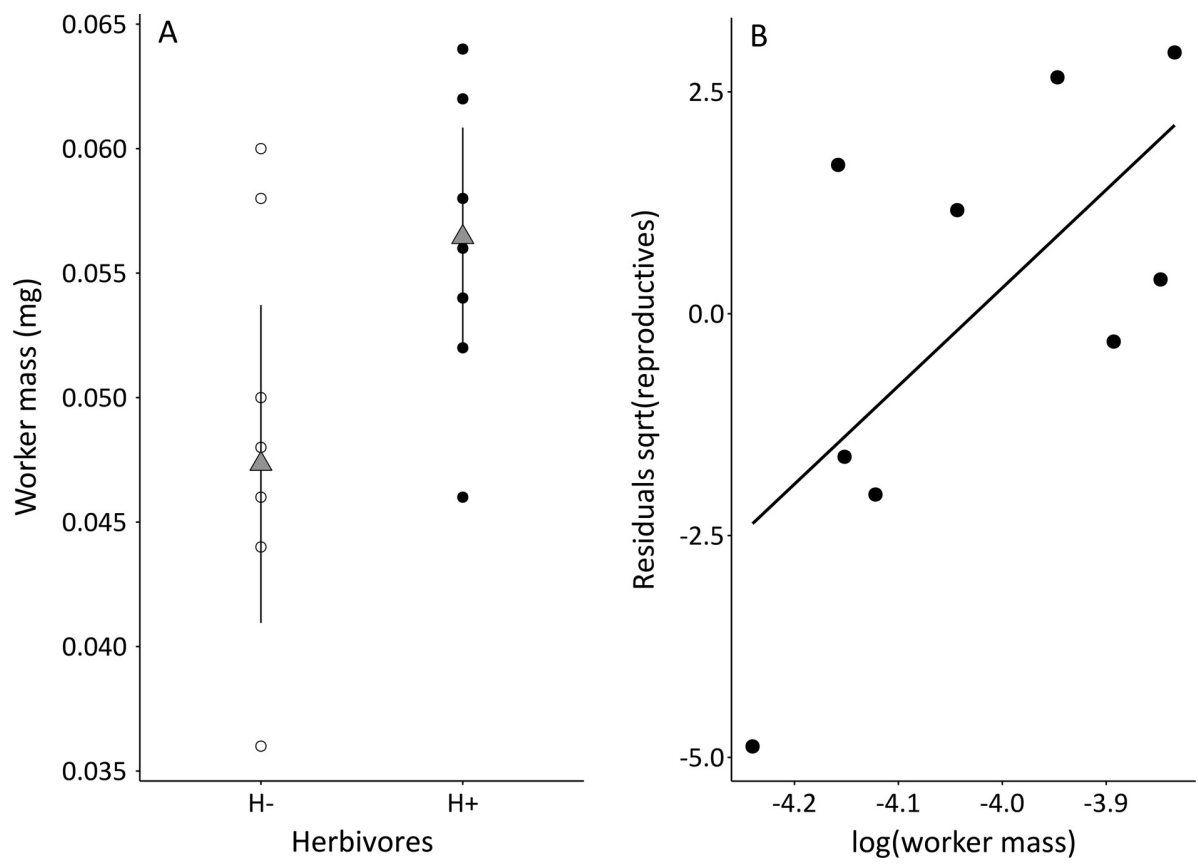

FIG. 2. (A) Worker mass (mean $\pm \mathrm{SE}$ ) for ants in the experimental manipulation (gray triangles). Ants with no access to prey in open circles $(\mathrm{H}-)$, while ants with access to insect prey in black circles $(\mathrm{H}+)$. Each circle is the mean mass of five workers per colony. (B) Relationship between worker mass (mean mass of 20 workers per colony in grams, log-transformed) and the residual values of the number of reproductives (i.e., alates; square-root transformed [sqrt]) per colony (adjusted $r^{2}=0.36$; intercept $=44.518$, slope $=11.057$ ).

dominated by Firmicutes (38.9\%), Proteobacteria (18.4\%), Bacteroides (12.5\%), and Actinobacteria (9.7\%; Fig. 3B). Unexpectedly, Fusobacteria were abundant in one ant colony $(\mathrm{H}-$, block $\mathrm{J})$; these bacteria, which are often pathogenic, accounted for $84.5 \%$ of the bacteria in that sample.

Analysis of beta diversity through PCoA also did not show any differences between treatments in the microbial assemblages in the ant gasters (Appendix S1: Fig. S1). The first three principal coordinates explained about $41 \%$ of the variation in the data with unweighted UniFrac and $72 \%$ with weighted Unifrac. The PERMANOVA test did not detect significant shifts in bacterial assemblages between treatments but suggested that environmental factors in different blocks might have influenced the structure of these assemblages when outlier blocks $\mathrm{A}$ and $\mathrm{J}$ were present in the analyses (Appendix S1: Table S2). However, no measured variables (e.g. number of scale insects, light, etc.) predicted changes in the bacterial assemblages (results not shown).

Similarly, bacterial abundance did not seem to be different between treatments. However, all samples had very few bacteria in the ants' gasters; as a result, $16 \mathrm{~S}$ counts were at or below the detection limit when analyzed with qPCR making it unreliable to perform statistical analyses on these data.

\section{Discussion}

Although A. octoarticulatus colonies can survive in the absence of insect prey, our results suggest that insect prey do contribute to colony nutrition and fitness. Thus, foraging for insect prey appears to be directly beneficial to A. octoarticulatus colonies, and plant defense may well be a by-product of this behavior. After a year excluding most potential animal prey, workers in the $\mathrm{H}$ - treatment recruited to protein-rich baits more often than their $\mathrm{H}+$ counterparts. This result is consistent with the geometric theory of insect nutrition of Raubenheimer and Simpson (1999), House (1969), and Waldbauer and Friedman (1991). They suggest that insects should balance their diet to reach an optimal concentration of essential nutrients required for development and survival when these are scarce in the environment. Allomerus octoarticulatus workers foraged more frequently at protein baits when insect prey was absent, suggesting that $A$. octoarticulatus actively seeks insect herbivores as a food source. This is supported by observations that a closely related ant, $A$. decemarticulatus, builds traps with fungi and plant debris to capture insects (Dejean et al. 2005, 2013, Orivel et al. 2017). We observed similar carton-like structures built by $A$. octoarticulatus that might play an important role on food acquisition (Leroy et al. 2010, Dejean et al. 2013, Orivel et al. 2017).

We expected that the experimental manipulation of insects would result in lower $\delta^{15} \mathrm{~N}$ and $\delta^{13} \mathrm{C}$ values for workers in the $\mathrm{H}-$ than the $\mathrm{H}+$ treatment, because these workers should have been more dependent on plantderived foods and therefore feeding at a lower trophic level. The stable isotope models showed that the treatment had a significant effect on $\delta^{13} \mathrm{C}$ values, but not on $\delta^{15} \mathrm{~N}$ 

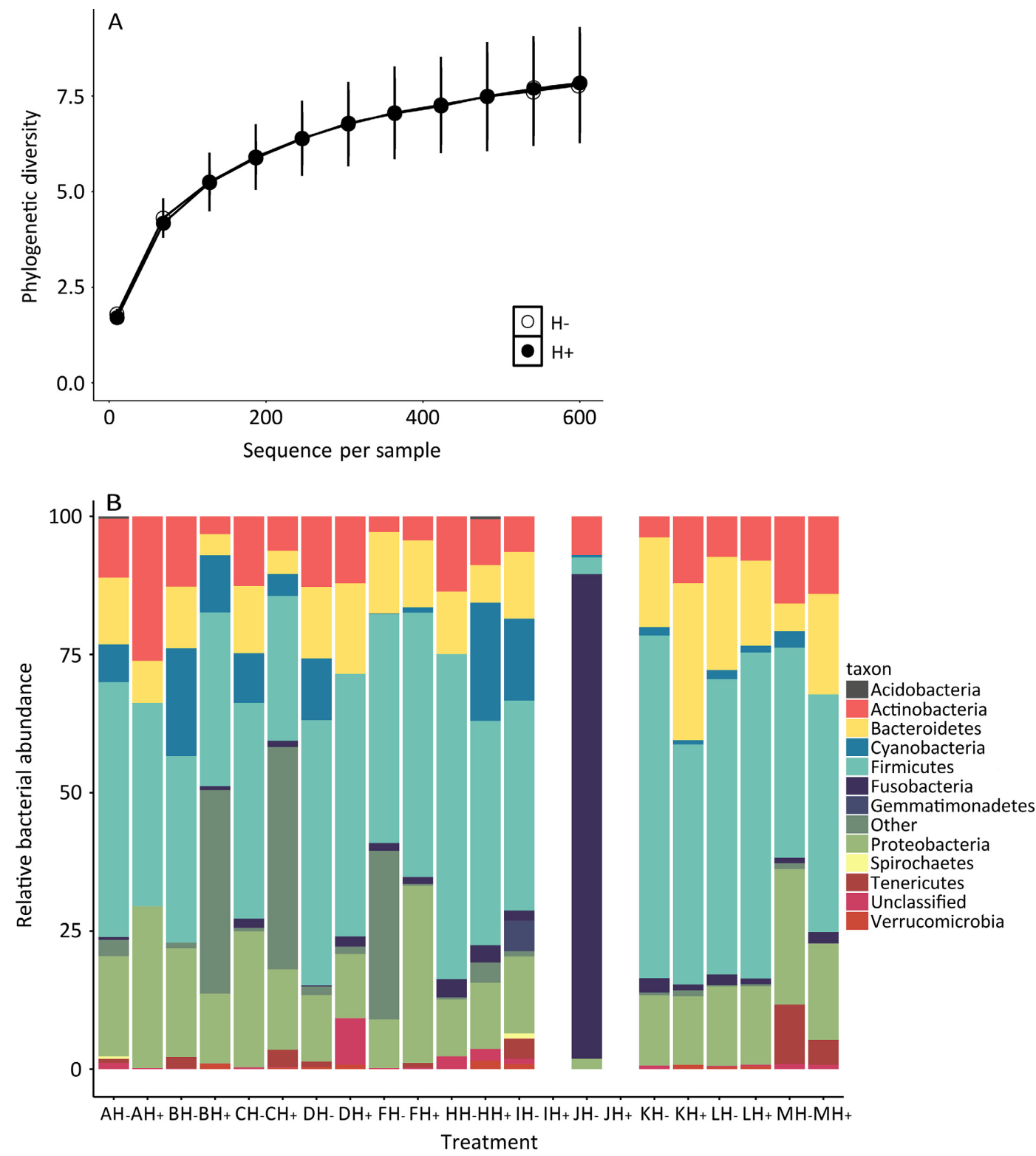

FIG. 3. (A) Phylogenetic diversity (PD) of bacteria in ant gasters with access to insect prey (solid circles) and without insect prey (open circles). Rarefaction plot obtained with a PD whole tree matrix. Values are mean $\pm \mathrm{SE}$. (B) Relative abundance of bacteria phyla in each sample. Colors in the bar graph represent the proportion of different operational taxonomic units (OTUs) clustered at $97 \%$ similarity. Samples are identified by their block letter followed by treatment ( $\mathrm{H}+$, access to insect prey; $\mathrm{H}-$, no insect prey).

values. Overall, we observed an average decrease of $0.6 \%$ for $\delta^{15} \mathrm{~N}$ and $0.72 \%$ for $\delta^{13} \mathrm{C}$ in $\mathrm{H}-$ ants compared to $\mathrm{H}^{+}$ ants (Fig. 1A). The average change in isotopic signature of ${ }^{13} \mathrm{C}$ is consistent with predictions that trophic level changes with differences of $\sim 0.5-1 \%$ for ${ }^{13} \mathrm{C}$. This is not the case for our values of ${ }^{15} \mathrm{~N}$, which are expected to change $3-5 \%$ for ${ }^{15} \mathrm{~N}$ per trophic level (Minagawa and Wada 1984, Sagers et al. 2000, Michener and Kaufman 2007). Ants might be able to balance their carbohydrate to nitrogen intake very precisely; hence ants that do not have access to insect prey might consume less protein, making them smaller, but with similar ratios of ${ }^{15} \mathrm{~N}$ relative to ${ }^{14} \mathrm{~N}$ incorporated in the ants' tissues. In the absence of insect prey, ant workers may eat more plant-derived food, food bodies and honeydew, which can have different $\delta^{13} \mathrm{C}$ signatures (Feldhaar et al. 2010, Brewitt et al. 2014, Parmentier et al. 2016), although this does not explain the similar $\delta^{15} \mathrm{~N}$ values between treatments. Alternatively, our experiment may not have had sufficient statistical power to detect treatment differences in $\delta^{15} \mathrm{~N}$ ratios.

All of the ants in the experiment were substantially ${ }^{15} \mathrm{~N}$ enriched compared to workers from naturally occurring 
A. octoarticulatus colonies from both the same site (Fig. 1B) and a nearby site (Davidson 2003). Since the experimental plants, ants, and soil were sourced from the same area as the reference samples, we did not expect the experimental manipulation to produce such a marked and general shift in $\delta^{15} \mathrm{~N}$. The ant colonies we studied range in size and age at the beginning of the experiment (Frederickson et al. 2012) but all of them had a similar ${ }^{15} \mathrm{~N}$ enrichment, implying that these factors might not explain the shift in ${ }^{15} \mathrm{~N}$ between experimental and naturally occurring ant colonies. It is possible that the season when the ants were collected or the specific location of the experimental plots drastically changed the isotopic values, as it has been demonstrated in other studies (e.g., Menke et al. 2010). This enrichment however does not invalidate the observed differences in isotope ratios between the experimental treatments.

Colony performance was consistent with the diet analyses; Allomerus octoarticulatus colonies had higher relative fitness (e.g., worker mass) when insects were part of their diet in this experiment. Although there was no statistically significant difference in colony growth or size between treatments, worker mass data showed that ants in the $\mathrm{H}$ - treatment were lighter than ants in the $\mathrm{H}+$ treatment. Thus, ant biomass was higher when insect prey was available. In naturally occurring colonies from the same population, colonies with heavier workers made more reproductives; such colonies may have more energy to invest in producing reproductives. These results support a previous study by Dejean et al. (2013), in which supplementation with insect herbivores increased the reproductive output of Allomerus decemarticulatus colonies. Although more experimental work needs to be done to determine if worker mass causes an increase in reproductive output, numerous field studies and mathematical models have shown that body mass is positively related to reproductive success of individuals and colonies, in large part because body mass influences metabolism, growth rate, mortality rate, and egg size (Banse and Mosher 1980, Juliano 1985, Savage et al. 2004). For example, workers with higher body mass could live longer, reducing the need for continuous worker production in the colony and allowing more resources to be invested in the production of reproductives. The results of this experiment add to those of earlier studies of ants that found that colony fitness can be inferred by the mass of adult reproductives and colony size (Gordon 1992, Deslippe and Savolainen 1994, Wagner and Gordon 1999, but see Ingram et al. 2013).

The assemblages of symbiotic bacteria in $A$. octoarticulatus gasters were not influenced by our experimental manipulation of insect prey. We would have expected this result if the microbiome were so tightly associated with the ants that it does not vary among ant colonies; however, we found that the bacterial assemblages in A. octoarticulatus gasters were very variable among colonies, negating our assumptions of a core bacterial community. This result, in concert with a decrease in worker mass when insect herbivores are absent, support a scenario were the gaster microbiome cannot compensate for a low-nutrient diet. Phylogenetic diversity was equal in both treatments and the composition of bacteria seemed to vary independently in each colony (Fig. 3). Furthermore, the variation in taxa among all samples shows that most bacteria are not tightly associated with ant diet. Neither weighted (relative abundance of bacteria included) nor unweighted (only presence/absence of bacteria) UniFrac analyses showed strong patterns in dissimilarity among the bacterial assemblages in the two treatments, and this was supported by a PERMANOVA test (Appendix S1: Table S2, Fig. S1). The PERMANOVA test shows a marginally significant block effect on microbiome assemblages, suggesting some environmental impact. Bacterial communities may be affected indirectly by environmental interactions with the host. For example, ants in some of the blocks did poorly; in block $\mathrm{G}$ neither of the colonies survived and in block $\mathrm{J}$, the $\mathrm{H}+$ colony did not survive to the end of the experiment and the $\mathrm{H}$ - colony was probably infected with a bacterial pathogen from the phylum Fusobacteria. This common bacterium was never in the same relative abundance found in the sample from block J. Thus, the question of what factors structure bacterial assemblages in A. octoarticulatus gasters remains unanswered.

Similar to other studies of bacterial assemblages in other arthropods, we found a complex and diverse community of bacteria. The bacterial taxonomic units in A. octoarticulatus, including OTUs in phyla such as Firmicutes, Bacteroidetes, and Proteobacteria, are mostly common inhabitants of arthropod guts (e.g., bees [CoxFoster et al. 2007], aphids [Oliver et al. 2010], ants [Van Borm et al. 2002, Seipke et al. 2013]). Bacterial groups such as $\gamma$-Proteobacteria and Bacteriodetes have been suggested to provide many benefits to ants (Zientz et al. 2005, Eilmus and Heil 2009). These two taxa make up over $20 \%$ of the bacteria found in A. octoarticulatus. One interesting finding was the high relative abundance of Actinobacteria, a taxon usually associated with soils, from which we found bacteria from the genus Pseudonocardia. This type of bacteria was also present in $37 \%$ of all Allomerus studied by Seipke et al. (2012b) and some of the Actinobacteria strains in this ant have antifungal properties (Seipke et al. 2012a, Gao et al. 2014). This is relevant because Allomerus ants need to maintain the carton trails they build with fungi and plant debris (Dejean et al. 2005). Pinto-Tomas et al. (2009) determined that in Attini ants, Pseudonocardia bacteria could produce antibacterial agents that help to defend their fungal gardens. Following Leroy et al. (2010), we emphasize that the association among fungi, ants, and bacteria might be more widespread and important that previously thought. The low absolute quantities of bacteria we measured in this system argue for caution in interpreting our results (Sanders et al. 2017); so while we do not expect highly conserved relationships between symbiotic bacteria and $A$. octoarticulatus workers or the 
microbiome compensating for a low-nutrient diet, we acknowledge the possibility of indirect benefits from the gaster microbiome not tested in this study.

In conclusion, mutualisms are surprisingly evolutionarily robust, despite a widespread expectation that partners should experience selection for selfish, cheating behavior (Axelrod and Hamilton 1981, Bronstein 2001, Douglas 2008). However, many mutualisms are likely stabilized by by-product benefits, in which partners are not under selection to cheat because their mutualistic behavior is not costly, even in the short term (Sachs et al. 2004, Mayer et al. 2014, Jones et al. 2015). We hypothesized that ant-plant relationships can be stabilized through byproduct benefits, especially when ants consume insect herbivores. We manipulated the presence of arthropod prey visiting $C$. nodosa plants to determine if the lack of an external protein source affects ant performance. We found that ant colonies actively forage for protein-rich food, and achieve higher colony biomass when they have access to arthropod herbivores. The mutualism between $C$. nodosa and A. octoarticulatus thus appears to have arisen through by-product benefits to the plant of the ants' foraging behavior. Ant colonies forage for and consume arthropod prey on their host plants, resulting in mutual benefits to host plants and ant colonies.

\section{Acknowledgments}

We thank Melissa Donnelly and Ishita Aggarwal for laboratory assistance. We are also grateful to Greg Booth, Antonio Coral, Rene Escudero, and Lisseth Flores Quispe for their help in the field. This research was made possible by an NSERC Discovery Grant and funding from the University of Toronto. We obtained permits from the Dirección General Forestal y de Fauna Silvestre of the Ministerio de Agricultura in Peru for fieldwork and sample collection (No. 394-2009-AG-DGFFSDGEFFS) and for molecular analyses of samples (No. 00462014-MINAGRI-DGFFSDGEFFS).

\section{Literature Cited}

Anderson, K. E., J. A. Russell, C. S. Moreau, S. Kautz, K. E. Sullam, Y. Hu, U. Basinger, B. M. Mott, N. Buck, and D. E. Wheeler. 2012. Highly similar microbial communities are shared among related and trophically similar ant species. Molecular Ecology 21:2282-2296.

Axelrod, R., and W. D. Hamilton. 1981. The evolution of cooperation. Science 211:1390-1396.

Banse, K., and S. Mosher. 1980. Adult body mass and annual production/biomass relationships of field populations. Ecological Monographs 50:355-379.

Blüthgen, N., G. Gebauer, and K. Fiedler. 2003. Disentangling a rainforest food web using stable isotopes: dietary diversity in a species-rich ant community. Oecologia 137:426-435.

Brewitt, K., J. Piñol, C. Werner, W. Beyschlag, X. Espadaler, N. Pérez Hidalgo, and C. Platner. 2014. Evaluating the importance of trophobiosis in a Mediterranean ant community: a stable isotope analysis. Insectes Sociaux 62:81-95.

Bronstein, J. L. 2001. The exploitation of mutualisms. Ecology Letters 4:277-287.

Caporaso, J. G., et al. 2010. QIIME allows analysis of highthroughput community sequencing data. Nature Methods 7: 335-336.
Cox-Foster, D. L., et al. 2007. A metagenomic survey of microbes in honey bee colony collapse disorder. Science 318: 283-287.

David, L. A., et al. 2014. Diet rapidly and reproducibly alters the human gut microbiome. Nature 505:559-563.

Davidson, D. W. 2003. Explaining the abundance of ants in lowland tropical rainforest canopies. Science 300:969-972.

Dejean, A., P. J. Solano, J. Ayroles, B. Corbara, and J. Orivel. 2005. Insect behaviour: arboreal ants build traps to capture prey. Nature 434:973.

Dejean, A., J. Orivel, V. Rossi, O. Roux, J. Lauth, P.-J. G. Malé, R. Céréghino, and C. Leroy. 2013. Predation success by a plant-ant indirectly favours the growth and fitness of its host myrmecophyte. PLoS One 8:e59405.

Deslippe, R. J., and R. Savolainen. 1994. Role of food supply in structuring a population of Formica ants. Journal of Animal Ecology 63:756-764.

Douglas, A. E. 2008. Conflict, cheats and the persistence of symbioses. New Phytologist 177:849-858.

Dowd, S. E., T. R. Callaway, R. D. Wolcott, Y. Sun, T. McKeehan, R. G. Hagevoort, and T. S. Edrington. 2008. Evaluation of the bacterial diversity in the feces of cattle using $16 \mathrm{~S}$ rDNA bacterial tag-encoded FLX amplicon pyrosequencing (bTEFAP). BMC Microbiology 8:125.

Dussutour, A., and S. J. Simpson. 2008. Description of a simple synthetic diet for studying nutritional responses in ants. Insectes Sociaux 55:329-333.

Dussutour, A., and S. J. Simpson. 2009. Communal nutrition in ants. Current Biology 19:740-744.

Dussutour, A., and S. J. Simpson. 2012. Ant workers die young and colonies collapse when fed a high-protein diet. Proceedings of the Royal Society B 279:2402-2408.

Eilmus, S., and M. Heil. 2009. Bacterial associates of arboreal ants and their putative functions in an obligate ant-plant mutualism. Applied and Environmental Microbiology 75:4324 4332.

Feldhaar, H., J. Straka, M. Krischke, K. Berthold, S. Stoll, M. J. Mueller, and R. Gross. 2007. Nutritional upgrading for omnivorous carpenter ants by the endosymbiont Blochmannia. BMC Biology 5:48.

Feldhaar, H., G. Gebauer, and N. Blüthgen. 2010. Stable isotopes: past and future in exposing secrets of ant nutrition (Hymenoptera: Formicidae). Myrmecological News 13:3-13.

Fernández, F. 2007. The myrmicine ant genus Allomerus Mayr (Hymenoptera: Formicidae). Caldasia 29:159-175.

Fiala, B., H. Grunsky, U. Maschwitz, and K. E. Linsenmair. 1994. Diversity of ant-plant interactions: protective efficacy in Macaranga species with different degrees of ant association. Oecologia 97:186-192.

Frederickson, M. E. 2005. Ant species confer different partner benefits on two neotropical myrmecophytes. Oecologia 143: 387-395.

Frederickson, M. E. 2009. Conflict over reproduction in an antplant symbiosis: why Allomerus octoarticulatus ants sterilize Cordia nodosa trees. American Naturalist 173:675-681.

Frederickson, M. E. 2013. Rethinking mutualism stability: cheaters and the evolution of sanctions. Quarterly Review of Biology 88:269-295.

Frederickson, M. E. 2017. Mutualisms are not on the verge of breakdown. Trends in Ecology and Evolution. https://doi. org/10.1016/j.tree.2017.07.001

Frederickson, M. E., and D. M. Gordon. 2009. The intertwined population biology of two Amazonian myrmecophytes and their symbiotic ants. Ecology 90:1595-1607.

Frederickson, M. E., A. Ravenscraft, G. A. Miller, L. M. Arcila Hernández, G. Booth, and N. E. Pierce. 2012. The direct and ecological costs of an ant-plant symbiosis. American Naturalist 179:768-778. 
Frederickson, M. E., A. Ravenscraft, L. M. Arcila Hernández, G. Booth, V. Astudillo, and G. A. Miller. 2013. What happens when ants fail at plant defence? Cordia nodosa dynamically adjusts its investment in both direct and indirect resistance traits in response to herbivore damage. Journal of Ecology 101:400-409.

Gao, H., S. Grüschow, J. Barke, R. F. Seipke, L. M. Hill, J. Orivel, D. W. Yu, M. Hutchings, and R. J. M. Goss. 2014. Filipins: the first antifungal "weed killers" identified from bacteria isolated from the trap-ant. RSC Advances 4:57267-57270.

Gaume, L., and D. McKey. 1999. An ant-plant mutualism and its host-specific parasite: activity rhythms, young leaf patrolling, and effects on herbivores of two specialist plant-ants inhabiting the same myrmecophyte. Oikos 84:130-144.

Gordon, D. M. 1992. How colony growth affects foreigner intrusion in neighboring harvester ant colonies. Behavioral Ecology and Sociobiology 31:417-427.

House, H. L. 1969. Effects of different proportions of nutrients on insects. Entomologia Experimentalis et Applicata 12:651-669.

Ingram, K. K., A. Pilko, J. Heer, and D. M. Gordon. 2013. Colony life history and lifetime reproductive success of red harvester ant colonies. Journal of Animal Ecology 82:540-550.

Janson, E. M., J. O. Stireman, M. S. Singer, and P. Abbot. 2008. Phytophagous insect-microbe mutualisms and adaptive evolutionary diversification. Evolution 62:997-1012.

Janzen, D. H. 1966. Coevolution of mutualism between ants and acacias in Central America. Evolution 20:249-275.

Janzen, D. H. 1975. Pseudomyrmex nigropilosa: a parasite of a mutualism. Science 188:936-937.

Jones, E. I., et al. 2015. Cheaters must prosper: reconciling theoretical and empirical perspectives on cheating in mutualism. Ecology Letters 18:1270-1284.

Juliano, S. A. 1985. The effects of body size on mating and reproduction in Brachinus lateralis (Coleoptera: Carabidae). Ecological Entomology 10:271-280.

Lane, D. 1991. 16S/23S rRNA sequencing. Pages 115-175 in E. Stackebrandt and M. Goodfellow, editors. Nucleic acid techniques in bacterial systematics. John Wiley \& Sons, New York, New York, USA.

Leimar, O., and R. C. Connor. 2003. By-product benefits, reciprocity, and pseudoreciprocity in mutualism. Pages 203-222 in P. Hammerstein, editor. Genetic and cultural evolution of cooperation. MIT Press, Cambridge, Massachusetts, USA.

Leroy, C., N. Séjalon-Delmas, A. Jauneau, M.-X. RuizGonzález, H. Gryta, P. Jargeat, B. Corbara, A. Dejean, and J. Orivel. 2010. Trophic mediation by a fungus in an ant-plant mutualism. Journal of Ecology 99:1-8.

Ley, R. E., et al. 2008. Evolution of mammals and their gut microbes. Science 320:1647-1651.

Lozupone, C. A., M. Hamady, S. T. Kelley, and R. Knight. 2007. Quantitative and qualitative beta diversity measures lead to different insights into factors that structure microbial communities. Applied and Environmental Microbiology 73:1576-1585.

Malé, P.-J., K. Turner, M. Doha, I. Anreiter, A. Allen, M. Sokolowski, and M. Frederickson. 2017. An ant-plant CGMPdependent, mutualism through the lens of $\mathrm{B}$, kinase genes. Proceedings of the Royal Society B. https://doi.org/10.1098/ rspb.2017.0896

Mayer, V. E., M. E. Frederickson, D. Mckey, and R. Blatrix. 2014. Current issues in the evolutionary ecology of ant-plant symbioses. New Phytologist 202:749-764.

Mcglynn, T. P., and E. L. Parra. 2016. Mechanisms of carbohydrate-fuelled ecological dominance in a tropical rainforest canopy-foraging ant. Ecological Entomology 41:226-230.

Menke, S. B., A. V. Suarez, C. V. Tillberg, C. T. Chou, and D. A. Holway. 2010. Trophic ecology of the invasive argentine ant: spatio-temporal variation in resource assimilation and isotopic enrichment. Oecologia 164:763-771.

Michener, R. H., and L. Kaufman. 2007. Stable isotope ratios as tracers in marine food webs: an update. Pages 238-282 in R. H. Michener and L. Kaufman, editors. Stable isotopes in ecology and environmental science. Second edition. Blackwell Publishing, Oxford, UK.

Minagawa, M., and E. Wada. 1984. Stepwise enrichment of ${ }^{15} \mathrm{~N}$ along food chains: further evidence and the relation between $\delta^{15} \mathrm{~N}$ and animal age. Geochimica et Cosmochimica Acta 48:1135-1140.

Moran, N. A. 2001. The coevolution of bacterial endosymbionts and phloem-feeding insects. Annals of the Missouri Botanical Garden 88:35.

Muegge, B. D., J. Kuczynski, D. Knights, J. C. Clemente, A. Gonzalez, L. Fontana, B. Henrissat, R. Knight, and J. I. Gordon. 2011. Diet drives convergence in gut microbiome functions across mammalian phylogeny and within humans. Science 332:970-974.

Ness, J. H., W. F. Morris, and J. L. Bronstein. 2009. For antprotected plants, the best defense is a hungry offense. Ecology 90:2823-2831.

Oliver, K. M., P. H. Degnan, G. R. Burke, and N. A. Moran. 2010. Facultative symbionts in aphids and the horizontal transfer of ecologically important traits. Annual Review of Entomology 55:247-266.

Orivel, J., P.-J. Malé, J. Lauth, O. Roux, F. Petitclerc, A. Dejean, and C. Leroy. 2017. Trade-offs in an ant-plant-fungus mutualism. Proceedings of the Royal Society B 284:20161679.

Parmentier, T., S. Bouillon, W. Dekoninck, and T. Wenseleers. 2016. Trophic interactions in an ant nest microcosm: a combined experimental and stable isotope $\left(\delta^{13} \mathrm{C} / \delta^{15} \mathrm{~N}\right)$ approach. Oikos 125:1182-1192.

Pinto-Tomas, A. A., M. A. Anderson, G. Suen, D. M. Stevenson, F. S. T. Chu, W. W. Cleland, P. J. Weimer, and C. R. Currie. 2009. Symbiotic nitrogen fixation in the fungus gardens of leaf-cutter ants. Science 326:1120-1123.

Pitman, N. C. A. 2008. An overview of the Los Amigos watershed, Madre de Dios, southeastern Peru. Washington, D.C., USA. http://cicra.acca.org.pe/espanol/paisaje_biodiversidad/ los-amigos-overview9.pdf

Pringle, E. G., R. Dirzo, and D. M. Gordon. 2011. Indirect benefits of symbiotic coccoids for an ant-defended myrmecophytic tree. Ecology 92:37-46.

Quince, C., A. Lanzén, T. P. Curtis, R. J. Davenport, N. Hall, I. M. Head, L. F. Read, and W. T. Sloan. 2009. Accurate determination of microbial diversity from 454 pyrosequencing data. Nature Methods 6:639-641.

R Development Core Team. 2015. R: A language and environment for statistical computing. R Foundation for Statistical Computing, Vienna, Austria. ISBN 3-900051-07-0, URL http://www.R-project.org

Raubenheimer, D., and S. J. Simpson. 1999. Integrating nutrition: a geometrical approach. Entomologia Experimentalis et Applicata 91:67-82.

Russell, J. A., C. S. Moreau, B. Goldman-Huertas, M. Fujiwara, D. J. Lohman, and N. E. Pierce. 2009. Bacterial gut symbionts are tightly linked with the evolution of herbivory in ants. Proceedings of the National Academy of Sciences USA 106:21236-21241.

Sachs, J. L., U. G. Mueller, T. P. Wilcox, and J. J. Bull. 2004. The evolution of cooperation. Quarterly Review of Biology 79:135-160.

Sagers, C. L., S. M. Ginger, and R. D. Evans. 2000. Carbon and nitrogen isotopes trace nutrient exchange in an ant-plant mutualism. Oecologia 123:582-586. 
Sanders, J. G., S. Powell, D. J. C. Kronauer, H. L. Vasconcelos, M. E. Frederickson, and N. E. Pierce. 2014. Stability and phylogenetic correlation in gut microbiota: lessons from ants and apes. Molecular Ecology 23:1268-1283.

Sanders, J. G., P. Łukasik, M. E. Frederickson, J. A. Russell, R. Koga, R. Knight, and N. E. Pierce. 2017. Dramatic differences in gut bacterial densities correlate with diet and habitat in rainforest ants. Integrative and Comparative Biology. https://doi.org/10.1101/114512

Savage, V. M., J. F. Gilloly, J. H. Brown, and E. L. Charnov. 2004. Effects of body size and temperature on population growth. American Naturalist 163:429-441.

Seipke, R., J. Barke, M. Ruiz-Gonzalez, J. Orivel, D. Yu, and M. Hutchings. 2012a. Fungus-growing Allomerus ants are associated with antibiotic-producing Actinobacteria. Antonie van Leeuwenhoek 101:443-447.

Seipke, R. F., S. Grüschow, R. J. M. Goss, and M. I. Hutchings. $2012 b$. Isolating antifungals from fungus-growing ant symbionts using a genome-guided chemistry approach. Methods in Enzymology 517:47-70.

Seipke, R. F., J. Barke, D. Heavens, D. W. Yu, and M. I. Hutchings. 2013. Analysis of the bacterial communities associated with two ant-plant symbioses. MicrobiologyOpen 2: 276-283.

Six, D. L. 2013. The bark beetle holobiont: why microbes matter. Journal of Chemical Ecology 39:989-1002.
Tillberg, C. V. 2004. Friend or foe? A behavioral and stable isotopic investigation of an ant-plant symbiosis. Oecologia 140:506-515.

Van Borm, S., A. Buschinger, J. J. Boomsma, and J. Billen. 2002. Tetraponera ants have gut symbionts related to nitrogen-fixing root-nodule bacteria. Proceedings of the Royal Society B 269:2023-2027.

Wagner, D., and D. M. Gordon. 1999. Colony age, neighborhood density and reproductive potential in harvester ants. Oecologia 119:175-182.

Waldbauer, G. P., and S. Friedman. 1991. Self-selection of optimal diets by insects. Annual Review of Entomology 36:43-63.

Wang, Q., G. M. Garrity, J. M. Tiedje, and J. R. Cole. 2007. Naive Bayesian classifier for rapid assignment of rRNA sequences into the new bacterial taxonomy. Applied and Environmental Microbiology 73:5261-5267.

Weber, M. G., and A. A. Agrawal. 2014. Defense mutualisms enhance plant diversification. Proceedings of the National Academy of Sciences USA 111:16442-16447.

Weyl, E. G., M. E. Frederickson, D. W. Yu, and N. E. Pierce. 2010. Economic contract theory tests models of mutualism. Proceedings of the National Academy of Sciences USA 107: $15712-15716$.

Zientz, E., H. Feldhaar, S. Stoll, and R. Gross. 2005. Insights into the microbial world associated with ants. Archives of Microbiology 184:199-206.

\section{SUPPORTING INFORMATION}

Additional supporting information may be found in the online version of this article at http://onlinelibrary.wiley.com/doi/ 10.1002/ecy.2036/suppinfo

\section{Data Availability}

Data associated with this paper are available from the Dryad Digital Repository: https://doi.org/10.5061/dryad.gf7bh. 